\title{
Reduction of Residual Stress of Welded Joint Using Vibrational Load
}

\author{
Shigeru Aoki ${ }^{12}$, Tadashi Nishimura ${ }^{2)}$ and Tetsumaro Hiroi ${ }^{1)}$ \\ 1)Department of Mechanical Engineering, Tokyo Metropolitan College of Technology, Higashi-Ohi, Shinagawa-ku, Tokyo, Japan \\ 2)Department of Production systems Engineering, Tokyo Metropolitan College of Technology, Higashi-Ohi, Shinagawa-ku, Tokyo, Japan
}

\begin{abstract}
Welding is widely used for construction of many structures. Since welding is a process using locally given heat, residual stress is generated near the bead. Tensile residual stress degrades fatigue strength. Some reduction methods of residual stress are presented and, for example, heat treatment and shot peening are practically used. However, those methods need special tools and are time consuming. In this paper, a new method for reduction of residual stress using vibrational load during welding is proposed. The proposed method is examined experimentally for some conditions. Two thin plates are supported on the supporting device and butt-welded using an automatic $\mathrm{CO}_{2}$ gas shielded arc welding machine. Residual stress in the direction of the bead is measured by using a paralleled beam X-ray diffractometer with scintillation counter after removing quenched scale chemically. First, residual stress for one pass welding for some excitation frequencies is examined. Material of specimen is rolled steel for general structure (JIS400). In this case, excitation frequencies are selected as the natural frequency and higher frequency. For both frequencies, tensile residual stress near the bead is significantly reduced. Second, residual stress for two pass welding for some excitation frequencies is examined. Specimens are welded at one side and then at reverse side. In this case, some frequencies are selected. For all frequencies, tensile residual stress near the bead is reduced at both sides of specimen. Finally, the proposed method is applied to the specimen made of high tensile strength steel. In this case, tensile residual stress near the bead is also reduced.
\end{abstract}

\section{INTRODUCTION}

Welding is widely used for construction of many structures. Since welding is a process using locally given heat, residual stress is generated near the bead. Tensile residual stress degrades fatigue strength. Some reduction methods of residual stress are presented and, for example, heat treatment and shot peening are practically used[1]. However, those methods need special tools and are time consuming. In other paper, it is effective to reduce residual stress using vibrational load after welding[2]. However, this method is not effective to all welding conditions.

In this paper, a new method for reduction of residual stress using vibrational load during welding is proposed. The proposed method is examined experimentally for some materials and some conditions. Two thin plates are supported on to the supporting device and butt-welded using an automatic $\mathrm{CO}_{2}$ gas shielded arc welding machine. Residual stress in the direction of the bead is measured by using a paralleled beam $\mathrm{X}$-ray diffractometer with scintillation counter after removing quenched scale chemically.

First, residual stress for one side welding for some excitation frequencies is examined. Specimens are welded along the groove. Welding is completed one pass. Material of specimen is rolled steel for general structure (IIS400). In this case, excitation frequencies are selected as the natural frequency and higher frequency. Second, residual stress for two sides welding for some excitation frequencies is examined. Specimens are welded on one side along the groove and then on back side. Welding is completed one pass on each side. In this case, some frequencies are selected. Finally, the proposed method is applied to the specimen made of high tensile strength steel. Specimens are welded on two sides. Residual stresses near the bead are measured for each condition. For comparison, some specimens are welded without vibrational load. Residual stresses of the specimen with vibrational load are compared with those without vibraional load.

\section{ONE SIDE WELDING}

Reduction of residual stress of one side welding is examined experimentally[3]. Figure 1 shows the specimen used in this experiment. Material of specimen is rolled steel for general structure (JIS400). Two thin plates are supported on to supporting devices by bolts as shown in Fig.2. Specimens are shaken by a small shaker during welding. Specimens are butt-welded using an automatic $\mathrm{CO}_{2}$ gas shielded arc welding machine. Diameter of the wire is $1.2 \mathrm{~mm}$. Voltage is $25 \mathrm{~V}$ and current is $200 \mathrm{~A}$. Groove is V-shaped and groove angle is $30^{\circ}$. Welding is completed through one pass and root opening is $1 \mathrm{~mm}$. Velocity of welding is $30 \mathrm{~cm} / \mathrm{min}$. Specimens are fixed on the supporting devices as show in Fig. 3 and shaken at the points $75 \mathrm{~mm}$ from the weldment . In order to transmit vibrational load from the shaker effectively, arms are connected with driving part of the shaker using plates of $45 \mathrm{~mm}$ width. Excitation frequency is chosen as $60 \mathrm{~Hz}$ which is the fundamental frequency of specimen of specimens installed as shown in Fig.3. In order to examine reduction effect of residual stress at non-resonant frequency, excitation frequency is chosen as $100 \mathrm{~Hz}$. The amplitudes of excitation are determined by current indicated at the amplifier of the shaker. The amplitudes of free edges of the specimens before welding are almost proportional to indicated current. For each current, peak to peak values of acceleration before welding are measured by accelerometer and listed in Table 1. Peak to peak values of displacement are calculated and listed in Table 1. For comparison, some specimens are welded without vibrational load.

Residual stress is measured by removing the quenched scale chemically and using a pararelled beam X-ray diffractometer with a scintillation counter. The conditions of the X-ray stress measurement are shown in Table 2. Measuring points are shown in Fig.4. Point C is on the bead, points $\mathrm{B}$ and $\mathrm{D}$ are $10 \mathrm{~mm}$ from the bead, points $\mathrm{A}$ and $\mathrm{E}$ are $50 \mathrm{~mm}$ from the bead. Residual stresses in the direction of the bead are maesured. 
Fig.5 shows residual stresses of the specimens shaken by $60 \mathrm{~Hz}$ vibrational load. Symbols are results for the specimens without vibrational load. For this condition, residual stresses are measured for three specimens. Symbols $\bigcirc$ are results for the specimens shaken during welding. From Fig.5, tensile residual stress on the bead, point $\mathrm{C}$, is significantly reduced when the specimens are shaken during welding. At points $B$ and $D, 10 \mathrm{~mm}$ from the bead, tensile residual stresses are also reduced. At points A and E, compressive residual stresses tend to be tensile. Tensile residual stresses decrease as the amplitude of excitation increases. Fig.6 shows residual stresses of the specimens shaken by $100 \mathrm{~Hz}$ vibrational load. Almost the same results as shown in Fig.5 are obtained. When the amplitude of excitation is large, 5.8A, reduction effect is small. It is considered that there is energy loss in joints connected by bolts which are between specimens and plates of experimental set-up in this condition. However, even if the excitation frequency does not coincide with the natural frequency of the specimen, the proposed method is also effective. In this case, the amplitude at the free edge of the specimen is small. welding.

From Fig.5 and Fig.6, it is obvious that tensile residual stresses near the bead can be reduced when the specimens are shaken during

\section{TWO SIDES WELDING}

Reduction of residual stress of two sides welding is examined experimentally. Figure 7 shows the specimen used in this study. Two thin plates are supported on to supporting devices by bolts as shown in Fig.2. Voltage is $25 \mathrm{~V}$ and current is 200A. Root opening is $0.5 \mathrm{~mm}$. Groove is X-shaped and groove angle is $45^{\circ}$. One side of the specimen is welded along the groove and then back side is welded along the groove. Welding is completed through one pass on each side. Velocity of welding is $30 \mathrm{~cm} / \mathrm{min}$. Specimens are fixed on the supporting devices as show in Fig.3. In order to examine reduction effect of residual stress at non-resonance frequency, excitation frequencies are chosen as $20 \mathrm{~Hz}$, $30 \mathrm{~Hz}$ and $40 \mathrm{~Hz}$. The amplitudes of excitation are determined by current indicated at the amplifier of the shaker. Current is fixed as $1 \mathrm{~A}$. Peak to peak values of acceleration before welding are measured at free edge of the specimen by accelerometer and listed in Table 3. Peak to peak values of displacement are calculated and listed in Table 3. For comparison, some specimens are welded without vibrational load.

Residual stresses are measured by the same method as one side welding. 5 points along the center line of the specimen are selected. These points are same as Fig.4. 5 points on the bead are also selected as shown in Fig.8. Point $\mathrm{c}$ is center of the specimen, points $\mathrm{b}$ and $\mathrm{d}$ are $20 \mathrm{~mm}$ from the center of the specimen, points a and e are $40 \mathrm{~mm}$ from the center of the specimen. Residual stresses in the direction of the bead are measured.

Fig.9 shows residual stresses on the center line of the specimen. Fig.9(a) shows results of the specimen without vibraional load. Fig9(b), Fig.9(c) and Fig9.(d) show results of the specimen shaken by $20 \mathrm{~Hz}, 30 \mathrm{~Hz}$ and $40 \mathrm{~Hz}$ vibrational load, respectively. Symbols and symbols $\boldsymbol{A}$ are results for residual stresses on one side and back side of the specimens, respectively. From these figures, tensile residual stress on the bead, point $C$, is significantly reduced when the specimens are shaken during welding. At points $B$ and $D, 10 \mathrm{~mm}$ from the bead, tensile residual stresses are also reduced. At points $\mathrm{A}$ and $\mathrm{E}$, compressive residual stresses tend to be tensile. Thus, it is obvious that tensile residual stresses near the bead can be reduced when the specimens are shaken during welding.

Fig.10 shows residual stresses on the bead of the specimen. Fig.10(a) shows results of the specimen without vibraional load. Fig10(b), Fig.10(c) and Fig.10(d) show results of the specimen shaken by $20 \mathrm{~Hz}, 30 \mathrm{~Hz}$ and $40 \mathrm{~Hz}$ vibrational load, respectively. Symbols and symbols $\boldsymbol{\Delta}$ are results for residual stresses on one side and back side of the specimens, respectively. From these figures, tensile residual stress on the center of the specimen, point $c$, is significantly reduced when the specimens are shaken during welding. At points $b$ and d, 20mm from the center of the specimen, tensile residual stresses are also reduced. At points a and e, compressive residual stresses tend to be tensile. Thus, it is obvious that tensile residual stresses near the bead can be reduced when the specimens are shaken during welding.

\section{APPLICATION TO WELDING OF HIGH STRENGTH STEEL}

The proposed method is applied to welding of high strength steel. Figure 11 shows the specimen used in this study. Material of specimen is high strength steel. Two thin plates are supported on to supporting devices by bolts as shown in Fig.12. Voltage is $25 \mathrm{~V}$ and current is 200A. Root opening is $0.5 \mathrm{~mm}$. Groove is X-shaped and groove angle is $45^{\circ}$. First, one side is welded along the groove and then back side is welded along the groove. Welding is completed through one pass on each side. Velocity of welding is $30 \mathrm{~cm} / \mathrm{min}$. Specimens are fixed on the supporting devices as show in Fig.3. Excitation frequency is chosen as $31 \mathrm{~Hz}$, natural frequency of specimen. The amplitudes of excitation are determined by current indicated at the amplifier of the shaker. Current is fixed as 0.8A. Peak to peak values of acceleration before welding are measured at edge of the specimen by accelerometer and listed in Table 4. Peak to peak values of displacement are calculated and listed in Table 4. For comparison, some specimens are welded without vibrational load.

Residual stresses are measured by the same method and at the same points as two sides welding. Fig. 13 shows residual stresses on the center line of the specimen. Fig.13(a) shows results of the specimen without vibraional load. Fig13(b) shows results of the specimen shaken by $31 \mathrm{~Hz}$ vibrational load. Symbols $\mathbf{A}$ and symbols $\boldsymbol{\Delta}$ are results for residual stresses on one side and back side of the specimens, respectively. From these figures, tensile residual stress on the bead, point $\mathrm{C}$, is significantly reduced when the specimens are shaken during welding. At points $B$ and $D, 10 \mathrm{~mm}$ from the bead, tensile residual stresses are also reduced. At points $A$ and $E$, compressive residual stresses tend to be tensile. Thus, it is obvious that tensile residual stresses near the bead can be reduced when the specimens are shaken during welding.

Fig.14 shows residual stresses on the bead of the specimen. Fig.14(a) shows results of the specimen shaken by 31Hz. Symbols and symbols $\mathbf{\Delta}$ are results for residual stresses on one side and back side of the specimens, respectively. From these figures, tensile residual stress on the center of the specimen, point $c$, is significantly reduced when the specimens are shaken during welding. At points $b$ and d, 20mm from the center of the speciemn, tensile residual stresses are also reduced. At points a and e, compressive residual stresses tend to be tensile. 
Thus, it is obvious that tensile residual stresses near the bead can be reduced when the specimens are shaken during welding.

\section{CONCLUSIONS}

A new method for reduction of residual stress using vibrational load during welding is proposed. The proposed method is examined experimentally for some conditions. Two thin plates are supported on to the supporting device and butt-welded. Residual stress in the direction of the bead is measured First, residual stress for one side welding for some excitation frequencies is examined. Material of specimen is rolled steel for general structure (JIS400). In this case, excitation frequencies are selected as the natural frequency and higher frequency. Residual stresses in the direction of the bead are measured. For both frequencies, tensile residual stress near the bead is significantly reduced. Second, residual stress for two sides welding for some excitation frequencies is examined. Specimens are welded on one side and then on back side. For all frequencies, tensile residual stress near the bead is reduced on both sides of specimen. Finally, the proposed method is applied to the specimen made of high tensile strength steel. In this case, tensile residual stress near the bead is also reduced.

\section{REFERENCES}

1. American Society of Metals, Metals Handbook, 1983, pp.856-895

2. Gnirss.G, "Vibration and Vibratory stress relief. Historical Development, Theory and Practical Application", Welding in the World, 26-11/12, 1988, pp.4-8

3. Aki,S. and Nishimura,T., "Reduction of Residual Stress for Welding Joint Using Vibrational Load", Trans. of SMiRT-14, Vol.1, 1997, pp.385-392

Table 1 Relation between current applied to shaker and amplitude of free edge of specimen

\begin{tabular}{|c|c|c|c|}
\hline \multirow{2}{*}{ Frequency(Hz) } & \multirow{2}{*}{ Current(A) } & \multicolumn{2}{|c|}{ Amplitude } \\
\cline { 2 - 4 } & & Acc.(G) & Disp.(mm) \\
\hline \multirow{3}{*}{60} & 0.4 & 1.3 & 0.090 \\
\cline { 2 - 4 } & 2.0 & 5.5 & 0.370 \\
\cline { 2 - 4 } & 4.0 & 9.7 & 0.669 \\
\hline \multirow{3}{*}{100} & 2.0 & 2.5 & 0.062 \\
\cline { 2 - 4 } & 4.0 & 5.2 & 0.129 \\
\cline { 2 - 4 } & 5.8 & 7.4 & 0.184 \\
\hline
\end{tabular}

Table 3 Amplitude of free edge of specimen

\begin{tabular}{|c|c|c|c|}
\hline \multirow{2}{*}{ Frequency(Hz) } & \multirow{2}{*}{ Current(A) } & \multicolumn{2}{|c|}{ Amplitude } \\
\cline { 3 - 4 } & & Acc.(G) & Disp.(mm) \\
\hline 20 & 1.0 & 0.26 & 0.161 \\
\hline 30 & 1.0 & 1.99 & 0.548 \\
\hline 40 & 1.0 & 1.33 & 0.206 \\
\hline
\end{tabular}

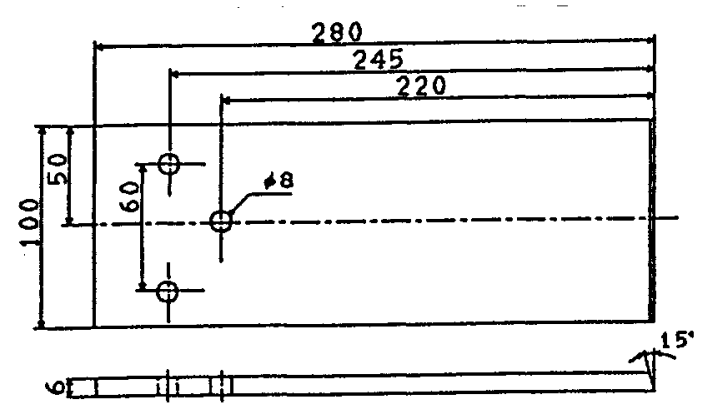

Fig1 Size and shape of specimen for one side welding
Table 2 Conditions for $\mathrm{X}$-ray stress measurement

\begin{tabular}{|l|l|}
\hline Characteristic X-rays & $\mathrm{Cr}-\mathrm{K} \alpha$ \\
\hline Diffraction plane & $\alpha$-Fe(211) \\
\hline Filter & Vanadium \\
\hline Stress determination & $\sin ^{2} \psi$ method \\
\hline Irradiated are & $2 \times 4 \mathrm{~mm}^{2}$ \\
\hline Tube voltage and current & $30 \mathrm{kV}, 8 \mathrm{~mA}$ \\
\hline Scan condition of $2 \theta$ & Step scanning \\
\hline Divergence angle shift & 1.0 \\
\hline Peak determination & Half value width method \\
\hline
\end{tabular}

Table 4 Amplitude of free edge of specimen

\begin{tabular}{|c|c|c|c|}
\hline Frequency(Hz) & Current(A) & \multicolumn{2}{|c|}{ Amplitude } \\
\cline { 3 - 4 } & & Acc.(G) & Disp.(mm) \\
\hline 31 & 0.8 & 0.78 & 0.200 \\
\hline
\end{tabular}

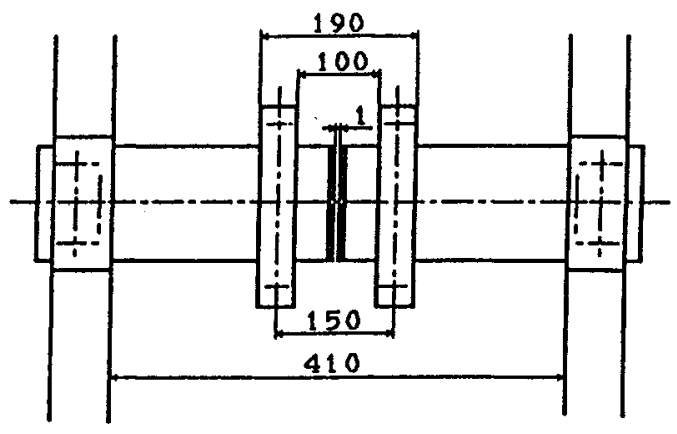

Fig.2 Experimental setup 


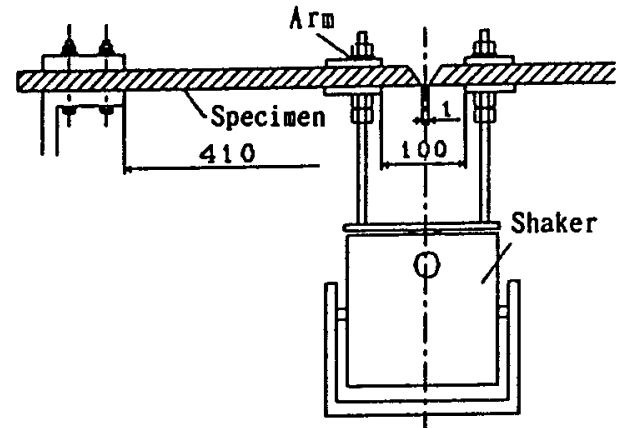

Fig.3 Supporting devices

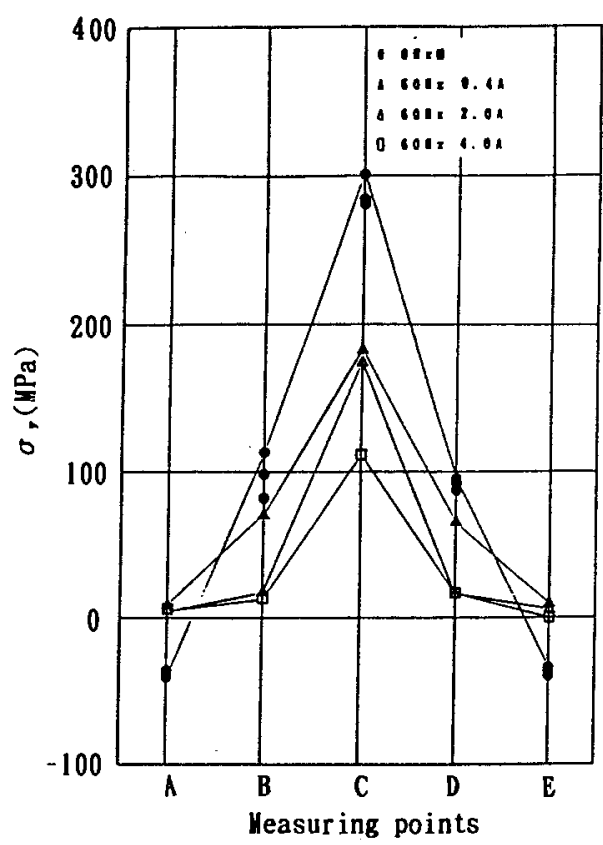

Fig.5 Residual stress for one side welding $(60 \mathrm{~Hz})$

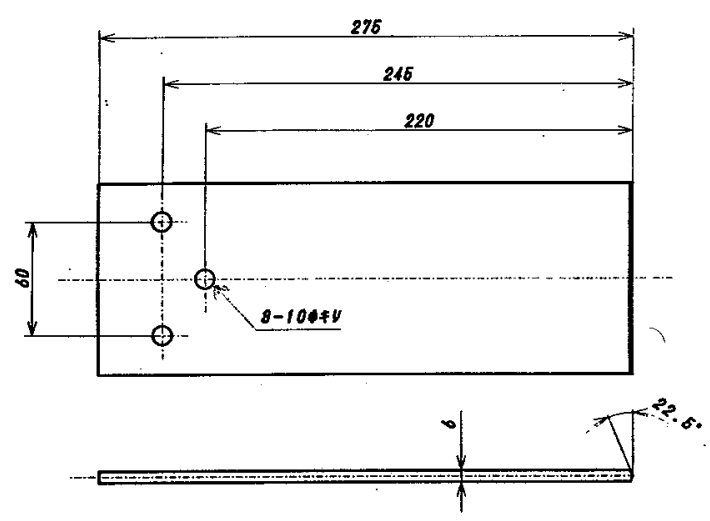

Fig7 Size and shape of specimen for two sides welding

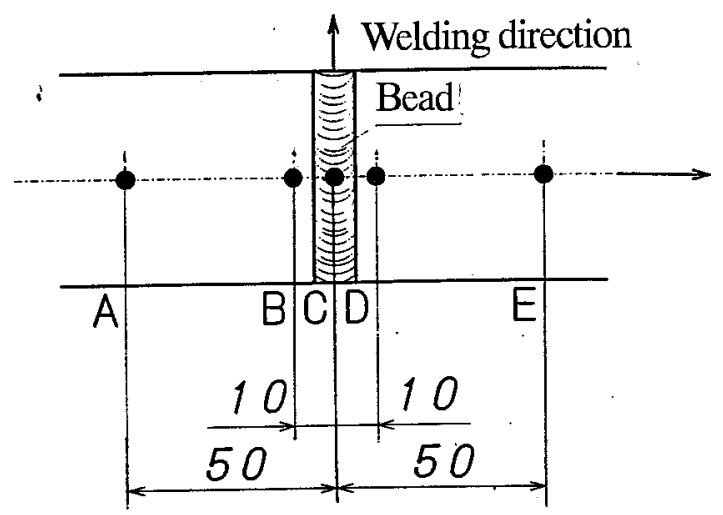

Fig.4 Measuring points of residual stress

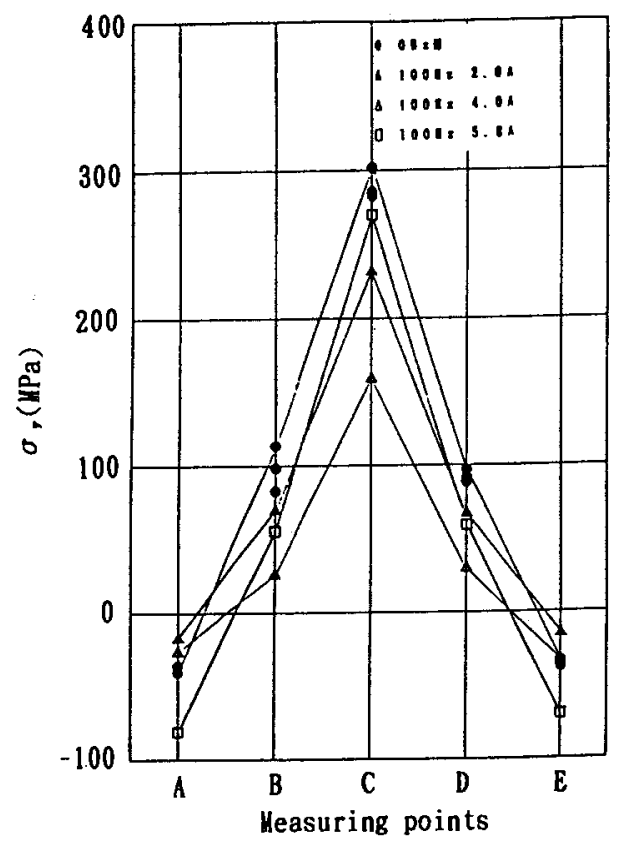

Fig.6 Residual stress for one side welding $(100 \mathrm{~Hz})$

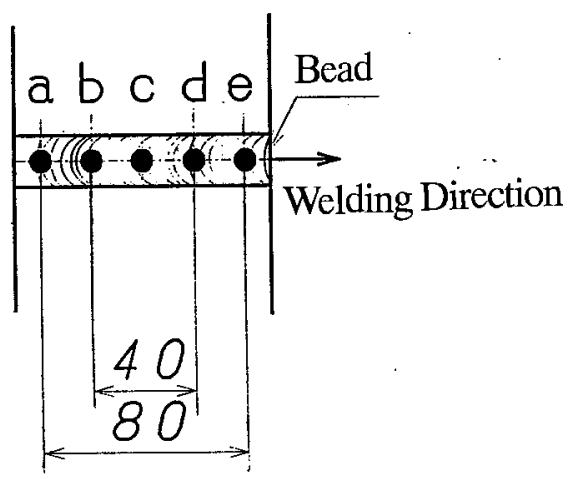

Fig.8 Measuring points of residual stress in the bead 


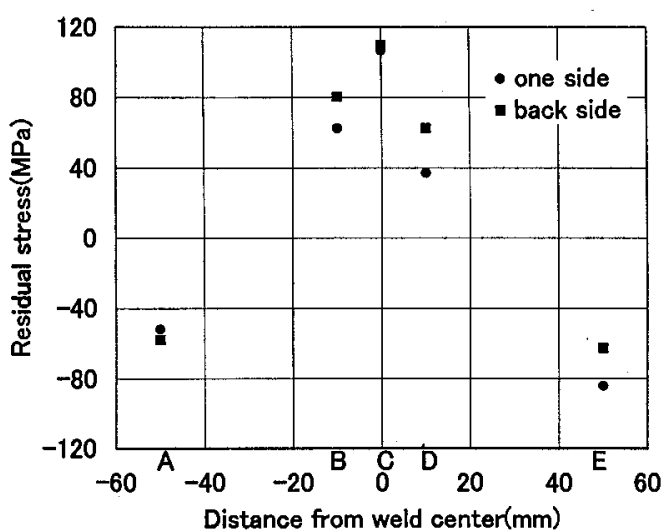

(a)without vibrational load

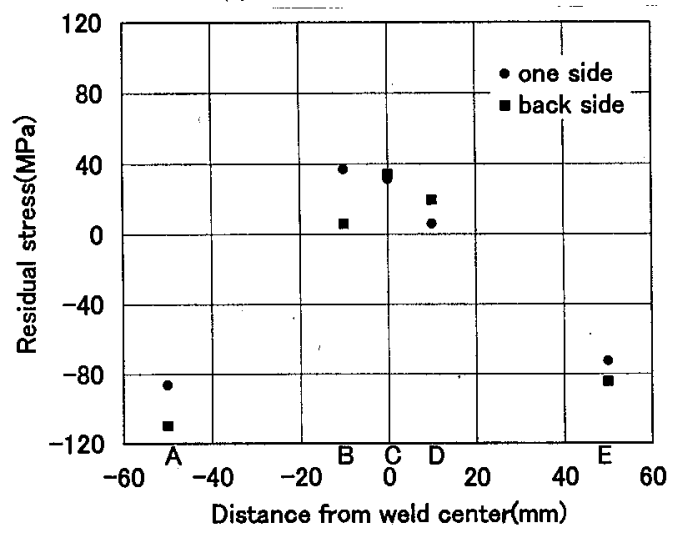

(c)with vibrational load $(30 \mathrm{~Hz})$

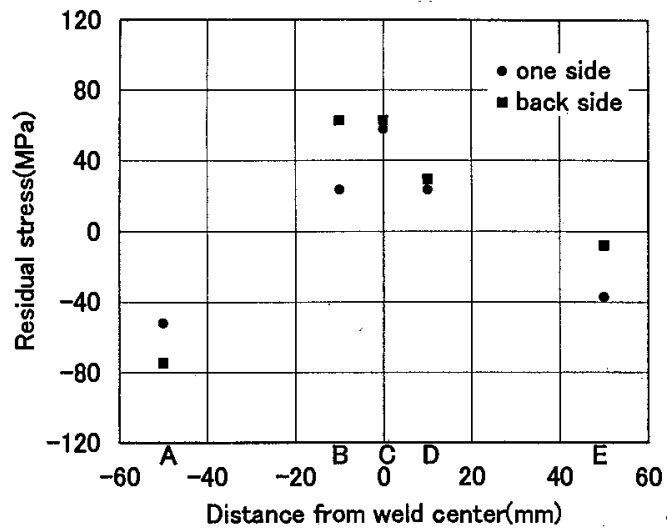

(b) with vibrational load $(20 \mathrm{~Hz})$

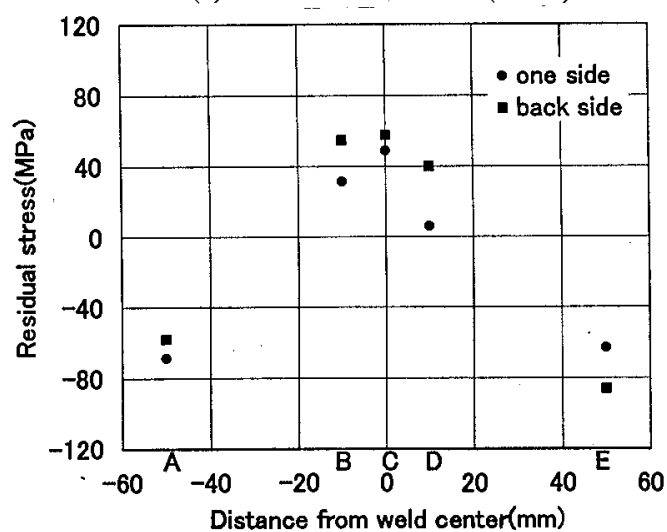

(d)with vibrational load $(40 \mathrm{~Hz})$

Fig.9 Residual stress on the center line of the specimen

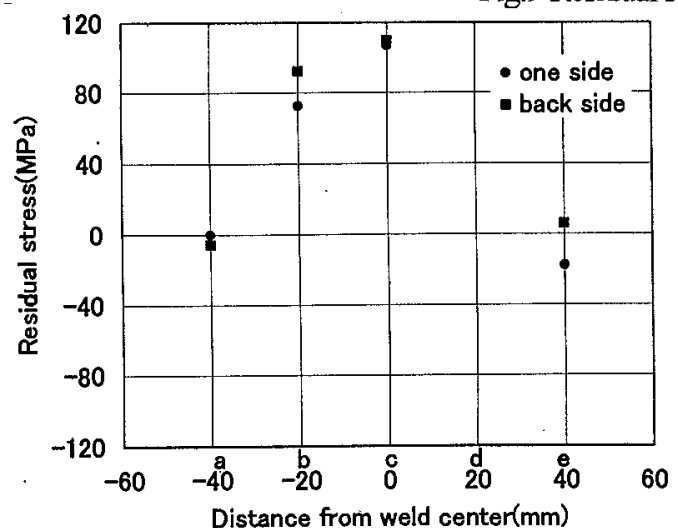

(a)without vibrational load

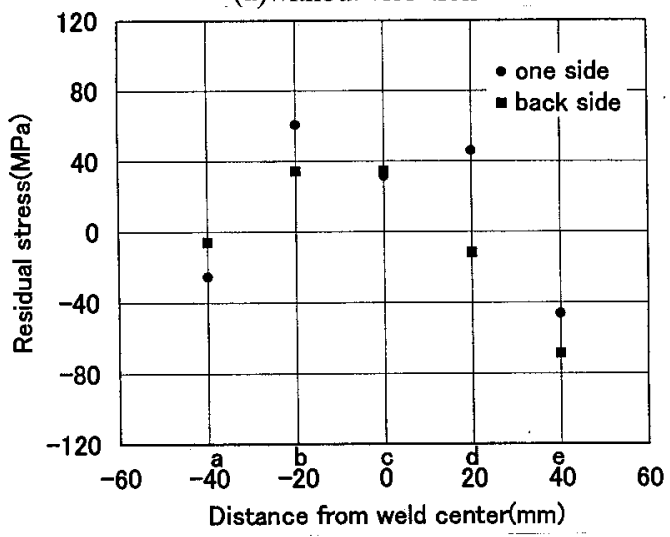

(c)with vibrational load $(\overline{30 \mathrm{~Hz}})$

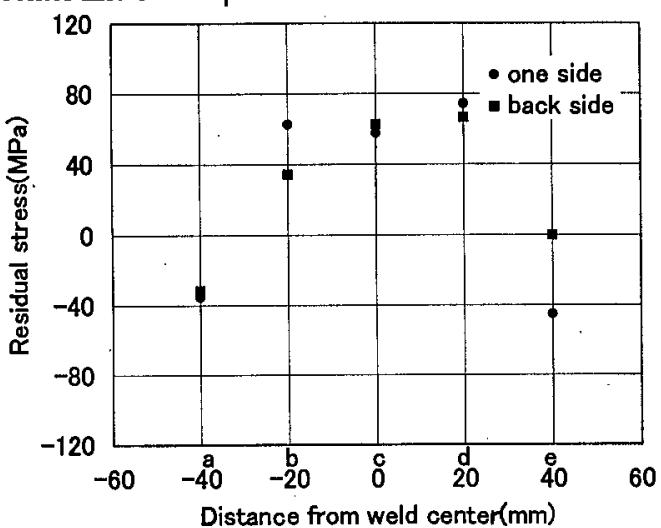

(b)with vibrational load $(20 \mathrm{~Hz})$

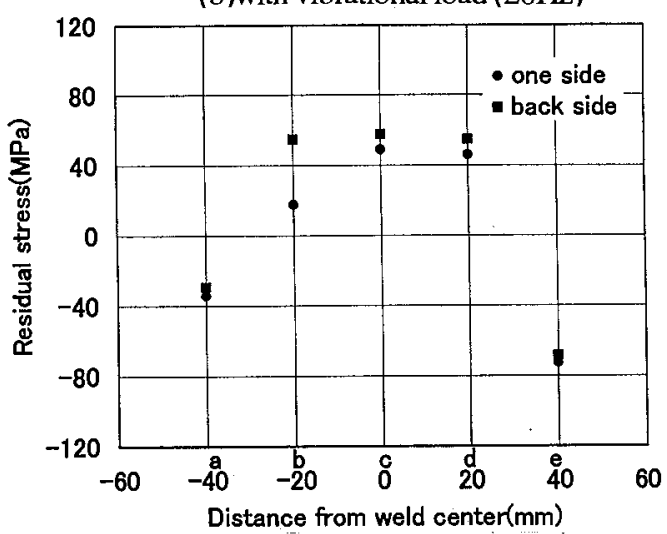

(d)with vibrational load $(40 \mathrm{~Hz})$

Fig.10 Residual stress on the bead 


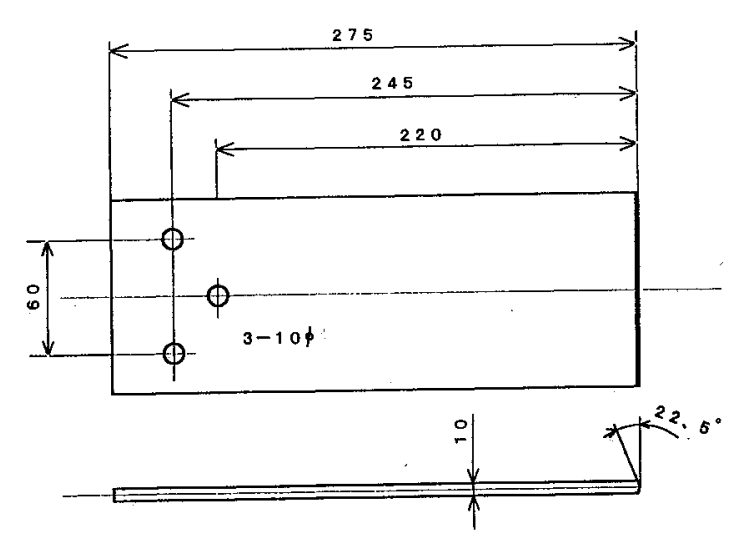

Fig11 Size and shape of specimen for welding of high strength steel

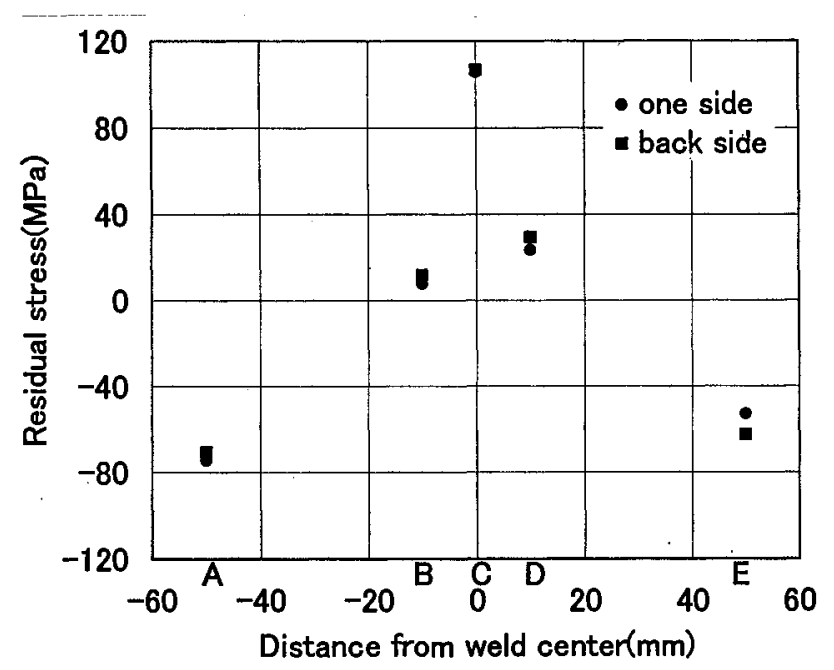

(a)without vibrational load

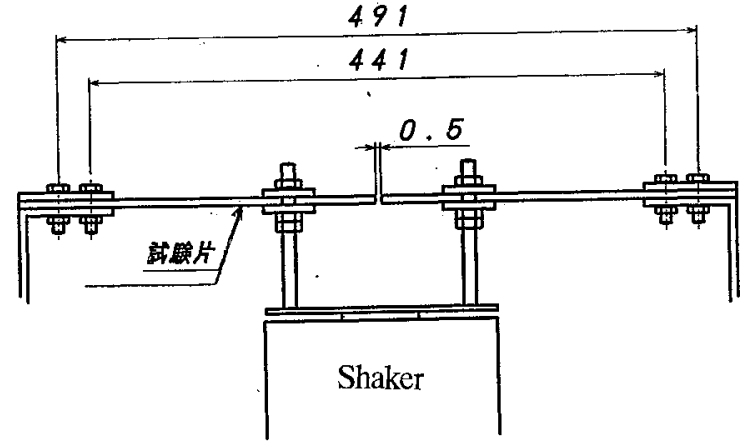

Fig.12 Supporting devices for welding of high strength steel

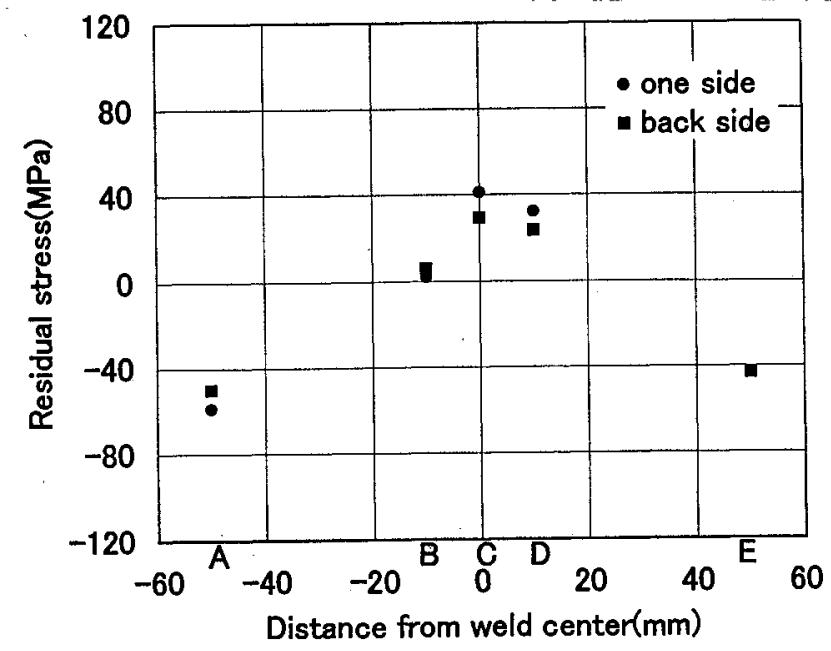

(b)with vibrational load $(31 \mathrm{~Hz})$

Fig.13 Residual stress on the center line of the specimen

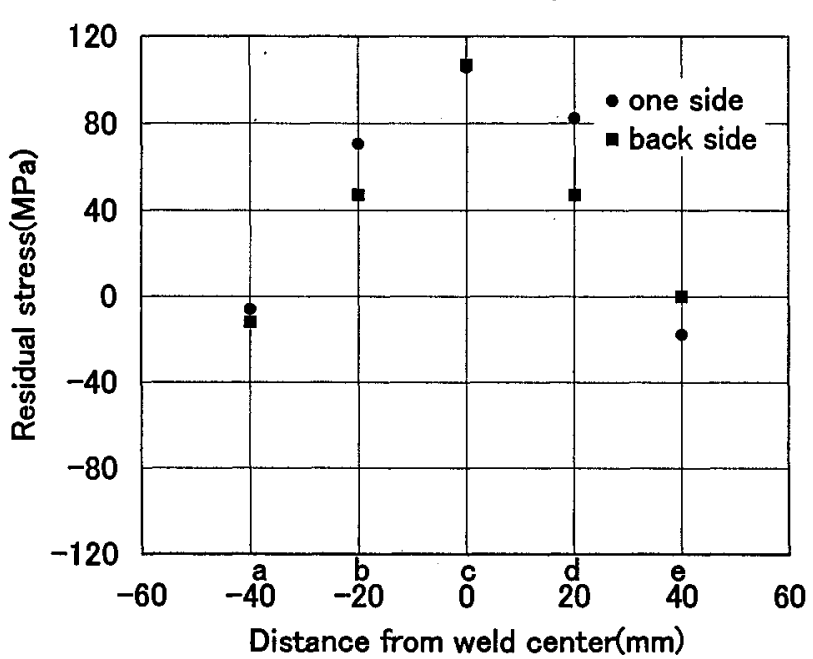

(a)without vibrational load

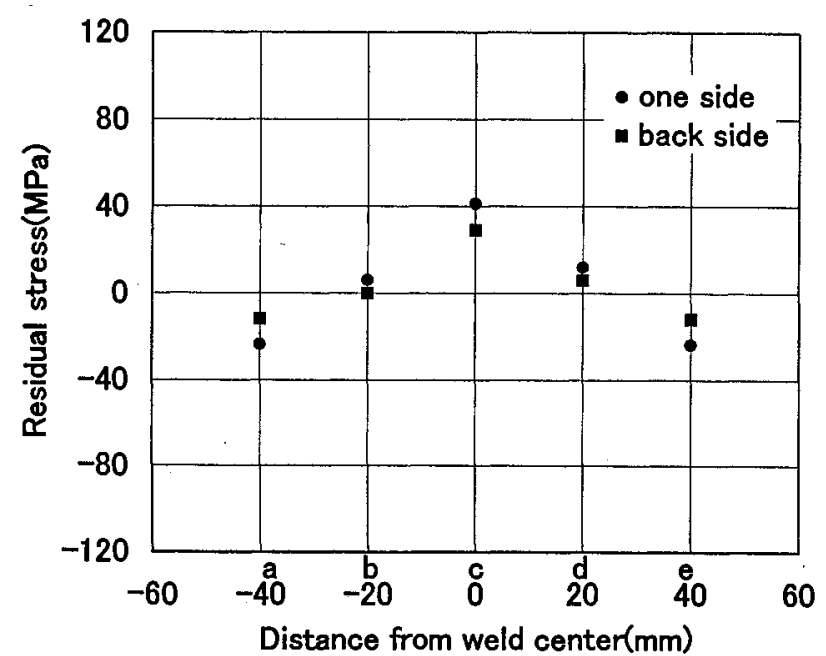

(b) with vibrational load $(31 \mathrm{~Hz})$

Fig.14 Residual stress on the bead 